\title{
Remote emergency learning during COVID-19 and its impact on university students perception of blended learning in KSA
}

\author{
Banan Bamoallem ${ }^{1}$. Samar Altarteer ${ }^{2}$
}

Received: 1 February 2021 / Accepted: 30 June 2021 / Published online: 13 July 2021

(c) The Author(s), under exclusive licence to Springer Science+Business Media, LLC, part of Springer Nature 2021

\section{Abstract}

This study explores the impact of remote emergency learning during the COVID19 pandemic on students' perception and acceptance of blended learning after the pandemic. The study applies the Community of Inquiry framework to understand the predictors and whether there is any statically significant correlation between the experience of remote teaching and students' perception and acceptance of the blended learning mode in the future as a stage in the gradual return to normal life after the pandemic. In addition to examining the correlation between students' perception of cognitive, teaching and social presences on their perception of blended learning, the correlation between technological and financial factors as well as demographic data on the intention to enrol in blended learning in the future is examined. The study surveyed one hundred and fifteen students from female Saudi Universities who are enrolled in a design major. The results revealed that the teaching, cognitive and social presences constructs are predictors of students' perception and acceptance of blended learning. Further, the facilitating conditions and efforts expectancy are also predictors of the perception of blended learning. The study also found that there is a significant correlation between the CoI and the selected constructs from the UTAUT when it comes to studying students' perception of blended learning.

Keywords Blended learning · COVID-19 pandemic $\cdot$ Remote learning - Design Studio courses · Community of Inquiry (CoI) - Saudi Arabia · Students' attitudes · Educational technology $\cdot$ Learning experience $\cdot$ Students' engagements

Banan Bamoallem

banan.bamoallem@gmail.com

Samar Altarteer

samaraltarteer@gmail.com

1 College of Designs and Arts, Umm AlQura University, Mecca, Saudi Arabia

2 School of Design and Architecture, Dar Al-Hekma University, Jeddah, Saudi Arabia 


\section{Introduction}

Following the COVID-19 coronavirus outbreak in December 2019, the Saudi government represented by the Ministry of Health decided to limit peoples' interaction and impose a lockdown to contain the spread of the virus. To enable social distancing, on the 9th of March, universities, schools and many other sectors with high person density were closed and staff, students and other employees instructed to work from home ("MOE," 2020). This change disrupted the life system of almost everyone including people involved in educational institutes. It caused a sudden shift from brick and mortar to emergency remote teaching as this was the only way to ensure continuing education during the pandemic. Virtual and online classes were activated and there was rigorous overseeing and monitoring by the Ministry of Education concerning the performance of faculty and involvement of students to ensure the smoothness of the education experience ("MOE 1," 2020).

Although the majority of public universities and some private universities in Saudi Arabia now have online education and distance learning deanship, a limited number of faculty was involved in this process, as the majority have no knowledge or prior experience in online teaching (Tanveer et al., 2020). The faculty found themselves forced to adapt and in no time adjust the teaching strategies to deliver the remaining course material online. The Ministry of Education and the educational institutions supported the faculty by providing professional development. However, there is no doubt that this situation was new, not only to faculty, but also to students who might have felt isolated, and their learning experience threatened. In a webinar that involved the deans of online and distance learning from leading universities in Saudi Arabia, it was suggested that the challenge now in moving towards online and distance learning is to change the culture among both teachers and students; this special experience broke the psychological barrier to acceptance of such education method ("MOE 2," 2020). They added that this is the right time, and in fact a must, for the universities to seriously consider online education and adapt other self-learning/ directing tools ("MOE 2," 2020).

To plan for the academic year 2020-21 onwards, the Ministry of Education requested from all universities proposals for holistic solutions to plans and strategies for delivering courses in the following semesters. We believed that blended learning was a sensible and reasonable solution for a gradual transition, not only for its efficiency during the pandemic, but also for learning more effectively. Blended learning (BL) has largely been investigated by scholars, and several empirical studies proved its effectiveness. According to Singh and Reed (2001), blended learning is defined as "a learning approach in which more than one delivery method is used to enhance the achievement of the learning outcomes and the cost of the programs." A blended learning environment can enhance students' performance and achievement (Dickfos et al., 2014), elevate students' learning experience, create a conducive learning environment (Azizan, 2010; Wai \& Seng, 2014) and allow experiencing a conceptual change when compared to the traditional lecture-based class delivery Bazelais and Doleck (2018). Moreover, faculty 
use blended learning to enhance the self-directed learning skills of weak performing students (Onah et al., 2020). Such a system can help students become more responsible for taking charge of their own learning, have more power over when and how that learning would happen (Leidner \& Jarvenpaa, 1995) and develop self-reflection skills (Dickfos et al., 2014). This helps students define goals, make decisions, and evaluate their progress, which would improve the learning outcome. Further, blended learning can provide students with flexibility and accessibility that cannot be found elsewhere (Dickfos et al., 2014).

Although there are a few studies conducted to understand the effectiveness of blended learning in the Saudi Arabian higher educational system, (Alebaikan \& Troudi, 2010; Almalki, 2011; Alnahdi, 2019; Saifuddin, 2019), the concept of blended learning is relatively new in the country with only a small number of Saudi universities offer such blended educational systems ("SEU"). Consequently, there is little known about student's perception of this method at this stage. Therefore, this paper aims to investigate the impact of compulsory remote teaching of practical studio courses during COVID-19 on attitudes towards blended learning from the KSA university students' perspective. To achieve this, it is important to understand the factors that affected the remote online learning experience and examine how these factors could influence the future acceptance of blended learning experience. The study will take design studio courses as a case study. These courses are vital and considered to be the core courses in the design majors. Knowledge transfer, passing technical information, and comprehending the content in such hands-on courses are completely different from theoretical courses. The crucial factor that affects the student's emergency e-learning experience is that such courses might differ from other theoretical courses which expected to have an impact on the attitudes towards blended learning.

\section{Theoretical framework}

Several studies were conducted to determine the factors that are expected to have an effect on students' remote emergency learning experience (Tanveer et al., 2020; Mailizar et al., 2021; Gopal et al., 2021; Almaiah et al., 2020; Sharma \& Alvi, 2021; Almossa, 2021).The Community of Inquiry and Acceptance model is a widely used model in studies of learning environments' impact on student's cognitive process. This model was extended in several previous studies to examine factors related to variant modes of online and blended learning. However, this model focuses on teaching and learning aspects but does not take into consideration the medium that is used for delivering the class and performing the required activities. Therefore, two dimensions from the Use of Technology (UTAUT) frameworks are incorporated to holistically evaluate the emergency online learning experience.

\subsection{The community of inquiry (Col) framework}

The Community of Inquiry framework/model, first introduced by Garrison et al. (2001), is founded on a collaborative constructivist perspective in the 
computer-mediated higher education learning and teaching experience. Garrison (2015) defines its aim as to "study and understand the influence of a purposeful learning environment on the cognitive processes of the individual. This is accomplished through the concurrent considerations of three interdependent elementscognitive, social, and teaching presence" (p. 58). The model assumes that learning happens collaboratively and is achieved within a community. So, it explains the dynamic and interdependent role of social presence, teaching presence and cognitive presence in which the meaningful deep experience lies in the overlap area between the three (Garrison et al., 1999). Since then, this framework has been extensively examined and used by scholars to study several factors related to variant modes of online and blended learning (Lam, 2015; Patwardhan et al., 2020; Siah et al., 2020), with 5,900 citations to date.

Teaching Presence has been shown to be a vital factor when it comes to determining students' satisfaction with the technology-based learning experience (Shea et al., 2005). It is defined as "the design, facilitation, and direction of cognitive and social processes for the realization of personally meaningful and educationally worthwhile learning outcomes" (Bogle et al., 2009). It is important to clarify that the teaching presence capitalizes on the faculty's role to create a community of inquiry incorporating social and cognitive presences (Garrison \& Kanuka, 2004). Methodologically, the teacher role here falls under three categories: Design and organisation, facilitating discourse, and direct instruction (Garrison et al., 2001). Design concerns the process and structure of the module material and experience as well as the teaching approaches, facilitation enables constructing and building individual meaning and confirming shared understanding, while direct instruction digs deep to identify any misconception and misunderstanding and gives feedback (Garrison \& Kanuka, 2004).

On the other hand, Cognitive Presence refers to the degree to which learners can develop and affirm knowledge/meaning via experiencing module activities, discussion and reflection (Garrison et al., 1999). The cognitive presence in the CoI model involves four phases that are established with triggering events, then exploration, integration and finally ending with the resolution (Garrison et al., 2001).

As with teaching and cognitive presences, Social Presence is defined by Garrison (2009) as "the ability of participants to identify with the community (e.g., course of study), communicate purposefully in a trusting environment, and develop interpersonal relationships by way of projecting their individual personalities". It is the extent of social and emotional connection the student feels in an online learning environment. The social presence consists of three sub-dimensions: affective responses, open communication, and group cohesion. This presence has proved to be a valuable factor in an effective online learning experience (Richardson \& Swan, 2001).

Based on this existing literature, the study proposed the following hypothesis:

$\mathrm{H}_{1}$ : Teaching presence positively affects students' perception of blended learning.

$\mathrm{H}_{2}$ : Cognitive presence positively affects students' perception of blended learning.

$\mathrm{H}_{3}$ : Social presence positively affects students' perception of blended learning. 
$\mathrm{H}_{4}$ : CoI positively affects students' perception of blended learning.

\subsection{Unified theory of acceptance and use of technology (UTAUT)}

As stated in the previous section, the Community of Inquiry framework was widely used to inform online and blended learning research and practice. Thus, this framework is used in the current study to help understand the predictors of the students' attitudes towards their emergency remote learning experience during the pandemic. Also, this study proposes that this framework will help in predicting the students' perception of the blended learning mode. However, there are other factors expected to affect the students' remote emergency learning experience and their perception of blended learning.is

The previous model focuses on teaching and learning aspects but does not cover the medium that is used for attending classes and completing course class activities. Thus, this study is incorporating additional constructs from the Unified Theory of Acceptance and Use of Technology (UTAUT). These two models were integrated in previous studies for different purposes and scenarios (e.g., Delmas \& Moore, 2019).

The UTAUT has been widely used by scholars to investigate the attitudes and acceptance of technologies in different contexts including online and blended learning in higher education (Delmas \& Moore, 2019). The framework is proposed and empirically validated by Venkatesh et al. (2003), evaluated by De Ruyter and Aarts (2004), further improved by Heerink et al. (2009) and since then has proved to have explanatory ability. The UTAUT aims to understand and explain users' attitudes and the factors that influence the attitudes towards the information technology used for emergency learning. The original model includes four main determinants but the current study will use two, namely facilitating condition, which is the organizational and technical infrastructure expected level in supporting the use of technology, and efforts expectancy, which describes the expectations the user has of the effort that is needed to use the technology (Venkatesh et al., 2003). Drawing upon the findings of these previous studies, the study generated the following hypothesis:

$\mathrm{H}_{5}$ : Effort expectancy positively affects students' perception of blended learning.

$\mathrm{H}_{6}$ : Facilitating condition positively affects students' perception of blended learning.

$\mathrm{H}_{7}$ : UTAUT positively affects students' perception of blended learning.

Since the emergency online teaching was the first experience of the students enrolled in Saudi universities face to face mode, it is expected that this experience will affect their perception of future blended learning experience. Therefore, the current study proposed the following hypotheses:

H8: Remote emergency learning (CoI and UTAUT) positively affects students' perception of blended learning.

H9: Students' perception of blended learning positively affects their behavioural intention towards blended learning. 
Because the study proposed that both models can predict the students' attitudes towards online teaching, the current study proposed the below hypotheses:

H10: There is a significant relationship between the UTAUT framework and CoI framework.

Previous scholars also acknowledge a variety of moderating variables that could affect the perception of the blended learning experience including Age, Gender and Academic level (Bogle et al., 2009; Venkatesh et al., 2003). Thus, the current study examines the moderating role of these demographic factors in addition to asking whether students pay for their education or not.

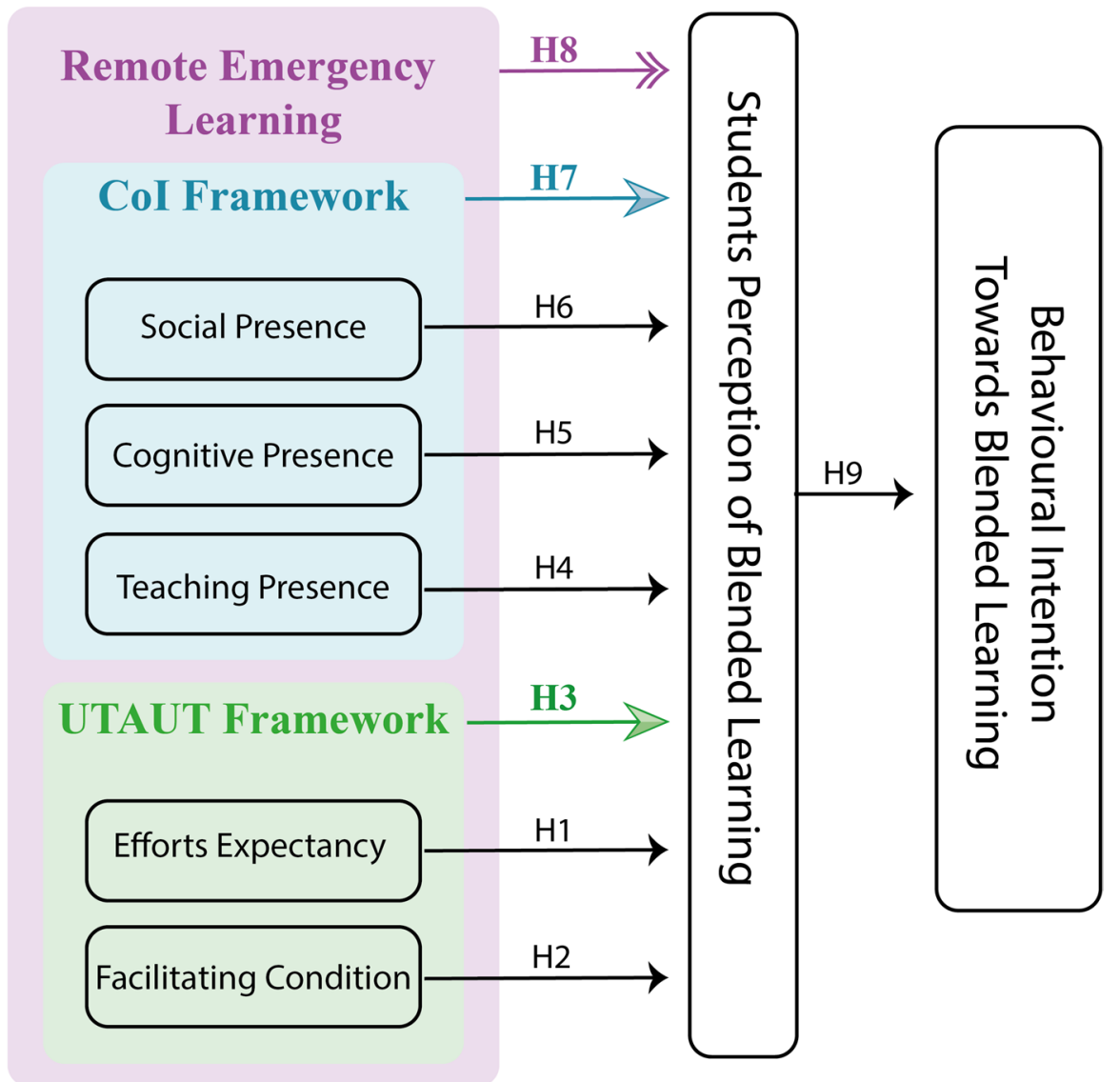

Fig. 1 The current research model 


\section{Research model}

Based on the CoI and the UTAUT models and literature review findings, the current study research model was constructed. Figure 1 shows the constructs and hypotheses as depicted in the arrows' directions.

\section{Research methodology}

In this paper, the researchers employed a mixed method, following both quantitative and qualitative approaches. The study used this method as it is considered to provide reliability and the obtained findings can be generalized (Fraenkel et al., 2018). The study was conducted right after the COVID-19 semester, in Summer (May and June of 2020).

\subsection{Survey instrument development}

An online bilingual questionnaire is thought to be the ideal data collection method for this study as it is easy to reach the target audience given the pandemic situation and it is faster in collecting responses.

This study used a modified version of the surveys developed for the CoI (Garrison et al., 2001) and the UTAUT (Venkatesh et al., 2003) models. Teaching Presence, Social Presence, and Cognitive Presence survey items were driven from the study conducted by Garrison et al. (2001), while Facilitating Conditions and Efforts Expectancy were derived from the study conducted by Venkatesh et al. (2003). The selected items were generated by the mentioned scholars guided by the construct's definitions. The survey was designed to collect responses to test the study hypothesis. To examine the survey validity, two researchers were provided with the definitions of each construct and asked to evaluate the survey and score its items. Based on their feedback, some items were slightly rephrased or eliminated. Additionally, the modified version of the survey was piloted among four students from public and private universities. Their comments regarding the wording and order of questions were considered and the researchers ensured that no further revision was required.

The final survey included 36 questions: teaching presences (8), social presence (6), cognitive presence (8), facilitating condition (4), efforts expectancy (2), perception of blended learning (3), behavioural intuition (1) and demographic questions [Table 1].

One open-ended question was added to enquire about the reasons behind the student perception of blended learning. Combining both qualitative and quantitative data enabled better explanation and confirmation of the findings (Wilkinson \& Birmingham, 2003). The answers to all questions were based on five choices ranging from Strongly agree to Strongly disagree. It was mandatory to answer all questions before submitting the survey. 


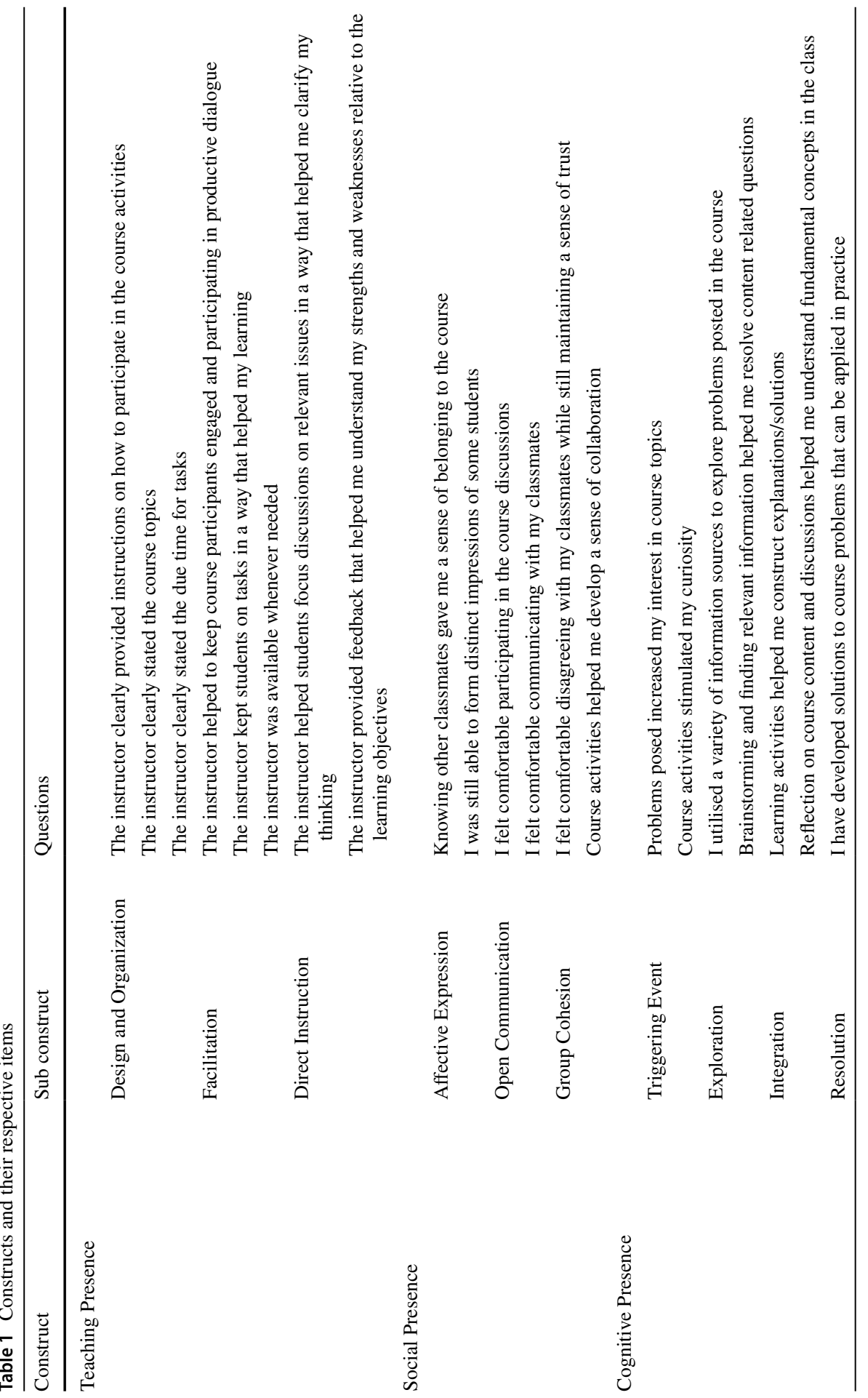




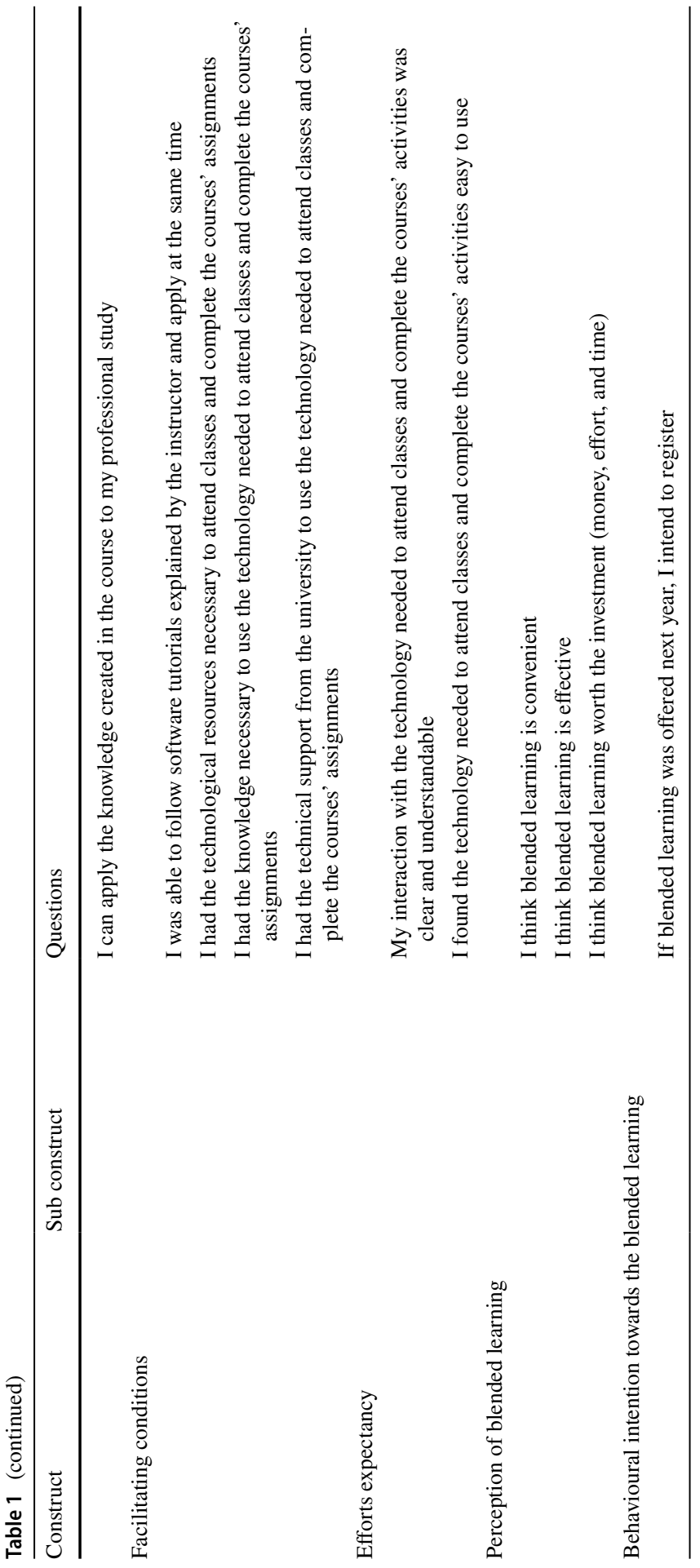




\subsection{Population and sampling}

The target population of the study is bachelor's degree students from design majors in female Saudi Universities, who were enrolled in design studio courses during the COVID-19 pandemic. The sample consisted of 115 female participants $-37.4 \%$ in the 2 nd academic year, $22.6 \%$ in the 3 rd year, $22.6 \%$ in the 4 th year, and $17.4 \%$ in the 1 st year. Most of the participants were Saudis in nationality (87.4\%). Participants ranged in age from 18 to 26, with a mean age of 20.88 . $65.2 \%$ of the participants do not pay university fees whilst $29.6 \%$ do pay university fees.

\subsection{Procedure}

The current study employs a non-probability, convenient sampling method. The survey was administered to participants online and distributed in social media, and emails. To verify that all participants were representatives of the study population, a question enquiring if the participant is a current design student at Saudi universities was asked. Only those who confirmed that were included in the study.

Since the questionnaire was a bit long, and students were on summer holiday, students were given the opportunity to participate in a drawing of two $150 \mathrm{SR}$ gift certificates from a local stationery and bookstore. All voluntarily participated students were required to accept the digital consent form prior to completing the survey. The research overview and the study target audience were clarified on the consent form. Also, it was made clear that the survey will be anonymous and strictly confidential, and there is no harm in participating in the study as the data will only be used for research purposes and that the participants can withdraw from the study at any time.

\subsection{Data Analysis}

The researchers used descriptive and inferential statistical methods for the purpose of achieving the study objectives and testing the hypotheses. Cronbach's Alpha was used to examine the reliability of the survey instrument. To test the normality, a visual check of the histograms of the data for each construct in all dimensions was performed. To evaluate the internal consistency of the survey measure, a Pearson Correlation Coefficient analysis was performed. The study also conducted a Kruskal-Wallis test to examine the impact of demographic factors on students' perception and intention of blended learning. 


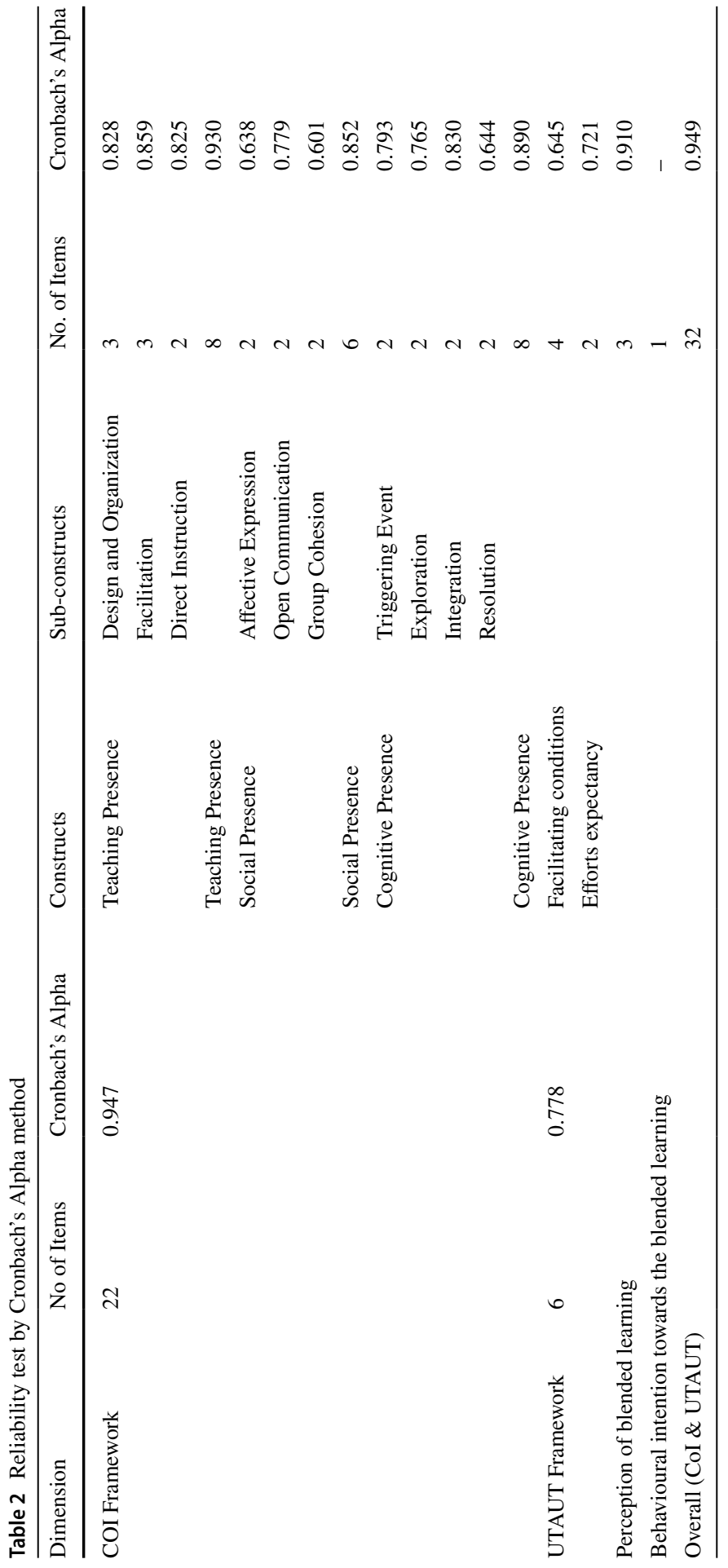




\section{Results}

This study aims to understand the impact of remote emergency learning during the COVID-19 pandemic on the attitudes towards blended learning (in the next semester or in the future), and to identify the academic factors that affect the attitudes towards the remote emergency learning experience.

Table 3 Pearson correlation test for items and constructs and sub-constructs

\begin{tabular}{|c|c|c|c|}
\hline Constructs & Sub-Constructs & Items & $\begin{array}{l}\text { Pearson Correlation of } \\
\text { the sub-constructs with } \\
\text { construct }\end{array}$ \\
\hline \multirow[t]{8}{*}{ Teaching Presence } & Design and Organization & A1 & $0.897^{* *}$ \\
\hline & & A 2 & \\
\hline & & A 3 & \\
\hline & Facilitation & B 4 & $0.960^{* *}$ \\
\hline & & B 5 & \\
\hline & & B 6 & \\
\hline & Direct Instruction & $\mathrm{C} 7$ & $0.918^{* *}$ \\
\hline & & $\mathrm{C} 8$ & \\
\hline \multirow[t]{6}{*}{ Social Presence } & Affective Expression & D 9 & $0.868^{* *}$ \\
\hline & & D 10 & \\
\hline & Open Communication & E 11 & $0.892^{* *}$ \\
\hline & & E 12 & \\
\hline & Group Cohesion & F 13 & $0.854^{* *}$ \\
\hline & & F 14 & \\
\hline \multirow[t]{8}{*}{ Cognitive Presence } & Triggering Event & G 15 & $0.839^{* *}$ \\
\hline & & G 16 & \\
\hline & Exploration & H 17 & $0.806^{* *}$ \\
\hline & & H 18 & \\
\hline & Integration & I 19 & $0.886^{* *}$ \\
\hline & & I 20 & \\
\hline & Resolution & $\mathrm{J} 21$ & $0.816^{* *}$ \\
\hline & & $\mathrm{J} 22$ & \\
\hline \multirow[t]{6}{*}{ UTAUT Framework } & Facilitating conditions & K 23 & $0.948^{* *}$ \\
\hline & & K 24 & \\
\hline & & K 25 & \\
\hline & & K 26 & \\
\hline & Efforts expectancy & $\mathrm{L} 27$ & $0.848^{* *}$ \\
\hline & & L 28 & \\
\hline \multirow[t]{3}{*}{ Perception of blended learning } & & M 29 & - \\
\hline & & M 30 & - \\
\hline & & M 31 & - \\
\hline
\end{tabular}

** $\mathrm{P}$-value $<0.01$ 
The results, using Cronbach's Alpha, revealed that the reliability of each subconstruct came in the range 0.601-0.910, with the reliability for each construct being 0.852-0.930; moreover, the reliability for each framework and the overall model was in the range $0.778-0.949$ which is acceptable and satisfied the researchers, although some sub-constructs showed a reliability coefficient $<0.7$, but still acceptable (Schmitt, 1996) [Table 2].

As for the normality check, it was found that all the data were normally distributed. A Pearson correlation coefficient test was conducted, and the results revealed that all Pearson correlation coefficients between each item and the total score of the constructs and total score of sub-constructs was in the range 0.630-0.936, which are positive, high, and statistically significant at level 0.01. Likewise, the correlation coefficient between each sub-construct and total score of constructs was in the range 0.806-0.960, which are positive, high, and statistically significant at level 0.01 [Table 3]. This means that the questionnaire enjoys a high level of internal consistency within its constructs and sub-constructs.

To evaluate if there is any impact of demographic factors on students' perception and intention of blended learning, a Kruskal-Wallis test was performed. The results showed that there are no statistically significant differences between the participants in their perceptions of blended learning according to their demographic factors.

\section{Hypotheses testing}

\subsection{The impact of remote emergency learning during the COVID-19 pandemic on the attitudes towards blended learning}

\section{a) The impact of CoI on students' perception of blended learning}

To test the following hypotheses:

$\mathrm{H}_{1}$ : Teaching presence positively affects students' perception of blended learning. $\mathrm{H}_{2}$ : Cognitive presence positively affects students' perception of blended learning.

$\mathrm{H}_{3}$ : Social presence positively affects students' perception of blended learning.

$\mathrm{H}_{4}$ : CoI positively affects students' perception of blended learning.

Table 4 Regression analysis for the effects of CoI on students' perception of blended learning

\begin{tabular}{lllll}
\hline Constructs & $\mathrm{B}$ & $\beta$ & $\mathrm{R}$ Square & Results \\
\hline Teaching presence & $0.599^{* *}$ & 0.439 & 0.193 & Supported \\
Cognitive presence & $0.616^{* *}$ & 0.384 & 0.148 & Supported \\
Social presence & $0.669^{* *}$ & 0.461 & 0.212 & Supported \\
CoI & $0.802^{* *}$ & 0.483 & 0.233 & Supported \\
**P-value $<0.01$. & & & &
\end{tabular}


Table 5 Regression analysis for the effects of UTAUT on students' perception of blended learning

\begin{tabular}{lllll}
\hline Sub-Constructs & $\mathrm{B}$ & $\beta$ & $\mathrm{R}$ Square & Results \\
\hline Efforts expectancy & $0.457^{* *}$ & 0.361 & 0.131 & Supported \\
Facilitating condition & $0.477^{* *}$ & 0.315 & 0.099 & Supported \\
UTAUT & $0.571^{* *}$ & 0.366 & 0.134 & Supported \\
\hline$* *$ P-value $<0.01$ & & & &
\end{tabular}

Table 6 Regression analysis for the effect of remote emergency learning (CoI and UTAUT) on students' perception of blended learning

\begin{tabular}{lllll}
\hline Constructs & B & $\beta$ & R Square & Results \\
\hline Remote emergency learning (CoI and UTAUT) & $0.855^{* *}$ & 0.488 & 0.238 & Supported \\
\hline$* *$ P-value $<0.01$ & & & &
\end{tabular}

A simple linear regression analysis was calculated to test the impact of each construct of $\mathrm{CoI}$ and their total separately on students' perception of blended learning. The results revealed that hypotheses $\mathrm{H}_{1}, \mathrm{H}_{2}, \mathrm{H}_{3}$ and $\mathrm{H}_{4}$ are supported since "teaching presence" has a significant positive impact on students' perception of blended learning $(\mathrm{B}=0.599$, $\mathrm{P}$-value $<0.01)$, "cognitive presence" has a significant positive impact on students' perception of blended learning $(B=0.616$, P-value $<0.01)$, "social presence" has a significant positive impact on students' perception of blended learning ( $\mathrm{B}=0.669$, $\mathrm{P}$-value $<0.01$ ), and "CoI" has a significant positive impact on students' perception of blended learning $(\mathrm{B}=0.802$, P-value $<0.01)$. [Table 4].

b) The impact of UTAUT on students' perception of blended learning

To test the following hypotheses:

$\mathrm{H}_{5}$ : Efforts expectancy positively affects students' perception of blended learning.

$\mathrm{H}_{6}$ : Facilitating condition positively affects students' perception of blended learning.

$\mathrm{H}_{7}$ : UTAUT positively affects students' perception of blended learning.

A simple linear regression analysis was calculated to test the impact of each sub-construct of UTAUT and their total separately on students' perception of blended learning. The results revealed that hypotheses $\mathrm{H}_{5}, \mathrm{H}_{6}$ and $\mathrm{H}_{7}$ are supported since "efforts expectancy" has a significant positive impact on students' perception of blended learning $(\mathrm{B}=0.457$, $\mathrm{P}$-value $<0.01)$, "Facilitating condition" has a significant positive impact on students' perception of blended learning $(\mathrm{B}=0.477$, P-value $<0.01)$ and "UTAUT" has a significant positive impact on students' perception of blended learning $(B=0.571$, $P$-value $<0.01)$. [Table 5]. 


\subsection{The impact of the current study proposed model (Col and UTAUT) on students' perception of blended learning}

To test the hypothesis:

$\mathrm{H}_{8}$ : Remote emergency learning (CoI and UTAUT) positively affects students' perception of blended learning

A simple linear regression analysis was calculated to test the impact of remote emergency learning (CoI and UTAUT) on students' perception of blended learning. The results revealed that hypothesis $\mathrm{H}_{8}$ is supported, since "remote emergency learning (CoI and UTAUT)" has a statistically significant positive impact on students' perception of blended learning $(\mathrm{B}=0.855$, $\mathrm{P}$-value $<0.01)$ [Table 6].

\subsection{The impact of students' perception of blended learning on their behavioural intention towards blended learning}

To test the hypothesis:

$\mathrm{H}_{9}$ : Students' perception of blended learning positively affects their behavioural intention towards blended learning.

A simple linear regression analysis was calculated to test the impact of students' perception of blended learning on their behavioural intention towards blended learning. The results revealed that hypothesis $\left(\mathrm{H}_{9}\right)$ is supported since "students' perception of blended learning" has a statistically significant positive impact on students' behavioural intention towards blended learning $(\mathrm{B}=1.018, \mathrm{P}$-value $<0.01)$ [Table 7].

The study also conducted a Kruskal-Wallis test to examine the impact of demographic factors on students' perception and intention of blended learning. The results showed that there are no statistically significant differences between the participants in their perceptions of blended learning according to their demographic factors.

\subsection{Col and UTAUT framework evaluation}

$\mathrm{H}_{10}$ : There is a significant relationship between the UTAUT framework and CoI framework

Table 7 Regression analysis for the effects of CoI on students' perception of blended learning

\begin{tabular}{|c|c|c|c|c|}
\hline Constructs & $\mathrm{B}$ & $\beta$ & R Square & Results \\
\hline Perception of blended learning & $1.018^{* *}$ & 0.849 & 0.721 & Supported \\
\hline
\end{tabular}




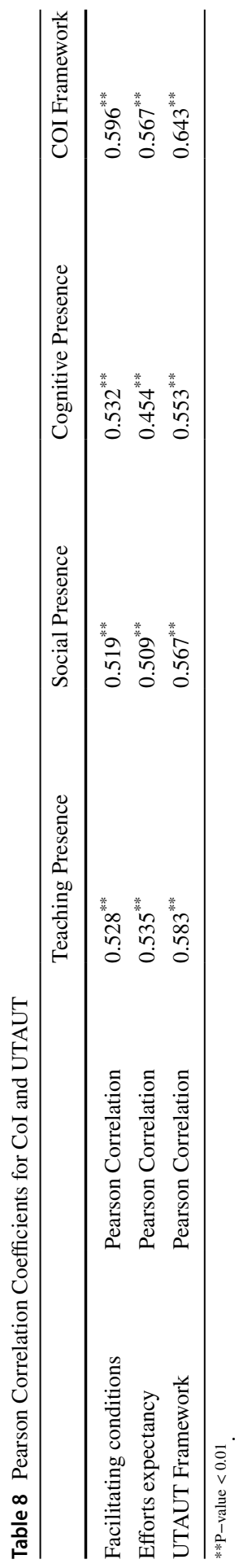


To study the relationship between the constructs of CoI and UTAUT, a Pearson correlation coefficient was used. The results revealed that "Facilitating conditions" has a positive significant correlation with CoI constructs amounting to 0.519-0.532 with p-values $<0.01$. "Efforts expectancy" has a positive significant correlation with CoI constructs amounting to $0.454-0.535$ with p-values $<0.01$. "UTAUT framework" has a positive significant correlation with CoI constructs amounting to $0.553-0.583$ with $\mathrm{p}$-values $<0.01$. "UTAUT framework" has a significant positive correlation with CoI framework amounting to 0.643 with p-value $<0.01$. [Table 8].

\section{Discussion}

In this study we explored the impact of emergency learning of practical studio courses during the COVID-19 pandemic on the students' attitudes towards the possible future use of blended learning. Our main goal is to highlight the factors that contribute to university students' attitudes towards blended learning in Saudi universities. The study combined two modified models, CoI and UTAUT, where the study hypotheses were examined. This exploration is important to advance the understanding of what factors play a critical role in the future use of blended learning among students.

In terms of CoI model, each of Teaching presence $\left(\mathrm{H}_{1}\right)$, Cognitive presence $\left(\mathrm{H}_{2}\right)$ and Social presence $\left(\mathrm{H}_{3}\right)$, separately, has a significant positive impact on students' perception of blended learning. Consequently, a positive effect can also be seen with the overall $\mathrm{CoI}\left(\mathrm{H}_{4}\right)$.

Teaching presence $\left(\mathrm{H}_{1}\right)$ has a positive contribution to the student perception of blended learning which can be explained by three main factors, design and organization, facilitation, and direct instruction which were successfully achieved during emergency learning. Firstly, in terms of design and organization students' comments emphasised the benefit of giving the courses syllabuses at the beginning of the academic semesters. Being aware of the course books, assigned teaching material, tasks, activities, supplementary materials sat a roadmap for the students and made them prepared for the sudden shift in the study delivery mode (Parkes \& Harris, 2002). This helped in delivering up to $80 \%$ of the course's syllabus though the sudden shift in teaching environment from the traditional face-to-face classes to online classes all at once according to Alshehri, et.al (2020). Secondly, facilitation was achieved by the positive instructors' actions which was also highlighted by students. It is important for the instructors to have a good interaction with students and engage them in a productive online education. This can be achieved by using more effective teaching methods to maintain students' interest in during the online class by involving them more in the discussion asking questions and giving them the chance to answer them which will enrich the online education. In addition, this positive instructor's performance also plays an important role in helping some students to overcome their shyness (Varela et al., 2012), as we noticed that they tend to participate more in online environments than in traditional environments. As pointed out by one student "There are some positives for blended learning, including that it allowed the shy student to communicate and inquire about what he did not understand easily and 
become involved in the class and participate". Furthermore, instructors should provide regular feedback for students about their progress in learning especially when peer-induced participation is lacking. Thirdly, direct instruction which can be seen in student appreciation and valuing the feedback from their instructors especially for design courses, as highlighted by a student "The positive thing that I noticed in the emergency learning is that the instructors can give feedback to one student about their design, but we can all benefit from that as we hear the discussion and information the instructor provides and may also share our opinions and experiences.". Having accessible, varied means of communication and quick responses between student and instructor play a leadership role and is important in some specific teaching and learning contexts, such as engineering courses (Szeto, 2015). This finding was supported also by research by Almalki (2011) and Alshehri, et.al (2020), where he found that students appreciated this form of communication and appeared to enjoy the flexibility in emailing the lecturer after attendances at the university.

A positive contribution to the student perception of blended learning was found in Cognitive presence $\left(\mathrm{H}_{2}\right)$ which was also explored using four different factors, triggering events, explorations, integrations and resolutions. In terms of triggering events, the courses activities triggered students' curiosity in stimulating their interest in exploring the course topics. This played in supporting the exploration factor in students. As this helped students not only in motivating them but also was more useful for students to adapt the self-directed learning approach gradually by using a variety of information sources to explore problems (Bao 2020, Alashwal 2019).

This motivated students in learning and thinking by being more self-committed to participate and self-initiated to interact with others in learning activities that positively and directly affect their learning performance as highlighted by the students' feedback which explains the integration factor. Resolution factor was achieved during emergency learning, as students were able to develop solutions using the knowledge they have that can be applied in practice. One student expressed that by saying "Blended learning will give us the ability to organize ideas and rethink the topics of the lessons, which makes it look more comprehensive than the ones we draw during traditional lectures in a limited time". This was also supported by (Law et al., 2019), who pointed out that blended learning is more effective than a traditional lecturetype in this regard.

In terms of Social presence $\left(\mathrm{H}_{3}\right)$ a positive contribution to the student perception of blended learning was found. This can be explained as a result of affective expression, open communication and group cohesion factors. The affective expression factor was resulted from the emotional bonding with group members before emergency learning as well as during. This bonding plays a role in the open communication factor as well, students continue to interact with the same group members in other courses or outside of classes by sharing knowledge and skills (Brackett and Rivers, 2014). This also helped in maintaining a sense of trust and collaborations between students which affect the group cohesion factor.

The findings of hypothesis $\mathrm{H}_{5}$ (Efforts expectancy) and $\mathrm{H}_{6}$ (Facilitating condition) testing were statistically significant, indicating evidence for substantial influence on students' perception of blended learning. Effort expectancy is another factor that plays a significant role in the adoption of blended learning for design studio 
courses due to the students being able to do related activity using the provided technology easily. This can be explained by the individual student experience in using social networking and the familiarity with different interfaces, which give them the ability to direct their attention to engage in discussions in more innovative ways as compared to face-to-face discussions (Tulaboev, 2013). In terms of faculty members, though the slowly and limited start of the online education since the early 2000s (Brackett and Rivers 2014), the numbers has increased throughout the years resulting from the huge improvement in the information and network technologies (Alashwal, 2019). This helped faculty members to quickly adopt the online learning environment to ensure normal teaching operation. In addition, faculty members were enrolled in extensive training courses to overcome these challenges of shifting into online platforms in a matter of days (Brackett and Rivers, 2014).

In terms of the Facilitating condition, the good support system for the technology available in the form of organizational, technological beside human support, is considered as one of the factors affecting students' perception of blended learning which was positively achieved during emergency learning which was supported also by Keskin (2019).

Therefore, we can conclude that the UTAUT dimension positively affects students' perception of blended learning $\left(\mathrm{H}_{7}\right)$. This positive result can also be explained by age as an important factor that might affect a student's willingness to adopt this system (Khechine et al., 2014).

In addition to the previous, students highlighted having the flexibility in both time and space for the study as one of the important factors. As most students emphasized the advantage of being able to save time during doing online classes rather than on campus which gave them more time to work on their own projects. However, some students raised the issue of instructors changing the online classes or exceeding lecture times, which made them feel as if they were studying all the time, causing stress and difficulties in focusing on the lecture. Therefore, this emphasized the importance of the flexibility accompanied by being punctual during online classes as a key factor to take the full advantage of flexibility that blended learning can provide. In addition, students appreciate the ability to view the recorded lectures and the course materials online and offline.

Despite these positive outcomes, some students were having external issues over using the technology. A small number of students highlighted having technical issues or bad network service besides the online learning system causing them problems in attending classes and learning. Therefore, we have to emphasise the importance of the internet connection with others as being essential to succeeding in a blended learning environment.

Another issue highlighted by the students is that not all the courses are suitable for online classes. Therefore, universities should consider the type of course, whereby theoretical topics may be more suitable for the online part and the practical topics should only be on campus.

Overall a positive impact of the two models' constructs was found, as one integrated model also led to a statistically significant positive impact on students' perception of blended learning $\left(\mathrm{H}_{8}\right)$. To the best of our knowledge, there is not enough research that examines the relationship between these two models and the impact 
of both of them together on students' perception of blended learning. This research shows that both CoI and UTAUT are significant predictors of perception of blended learning which also expected to have a positive impact on students' behavioural intention towards blended learning $\left(\mathrm{H}_{9}\right)$. Finally, the study also examined the relationship between the UTAUT framework and its constructs with the CoI framework and its constructs $\left(\mathrm{H}_{10}\right)$ and found that they have a significant positive correlation between them.

\section{Conclusion}

Higher education worldwide is affected by the COVID-19 pandemic. This disruption is challenging for educational institutions and students alike. It has forced the education sector to undergo a new road and indirectly contribute to opening up new opportunities with new challenges. This might prominently change the future of higher education in KSA and help it to gain more flexibility, building resilience and proactivity, which is expected to be the most vital education sector role needed at this time. Remote emergency teaching has also definitely changed the mindset of the students and their families in KSA and affected their perception and acceptance of other forms of education such as blended learning.

The question now is would Saudi universities adopt blended learning and whether students would choose to study under this system after the pandemic. Although the students who participated in this study showed a great interest in blended learning for design studio courses, the majority highlighted that the method of designing and dividing the course between online and in-class is the key factor in their satisfaction with the experience. In other words, the theoretical and lecturing part were found to be very effective online, while tutorials and feedback seem to be preferable in class. So, while blended learning can offer great flexibility and affordability for students, its planning has a great impact on the quality and acceptance of this mode of education. Unlike theoretical courses, studio courses require closer attention on how to design the course and divide the experience appropriately between online and faceto-face classes. Innovative technological solutions that boost student's interactivity in particular are expected to elevate the virtual education experience.

Addressing this important concern should help in orienting and preparing students for blended learning in order to avoid lower enrolment and disturbing the students' plans of study, and to avoid students' disengagement and dissatisfaction and any negative effects on the private universities.

With regard to the proposed framework, based on the results, the current study suggested that the CoI framework is dynamically associated with the UTAUT model in examining online and blended learning experiences and opens a new path for research in this area. We believe that the CoI framework requires further emphasis on the learner's efforts and the technological medium used. Also, there is a need to use this model again for an actual blended learning experience, not only an online emergency learning experience, to eliminate the possible impact of other variables such as gender, health concerns, depression, panic and stress caused by the pandemic. 


\section{References}

Alashwal, M. (2019). Faculty Perceptions and Use of Web 2.0 Tools in Saudi Arabian Higher Education.

Alebaikan, R., \& Troudi, S. (2010). Blended learning in Saudi universities: Challenges and perspectives. ALT-J, 18(1), 49-59.

Almaiah, M. A., Al-Khasawneh, A., \& Althunibat, A. (2020). Exploring the critical challenges and factors influencing the E-learning system usage during COVID-19 pandemic. Education and Information Technologies, 25(6), 5261-5280. https://doi.org/10.1007/s10639-020-10219-y

Almalki, A. (2011). Blended learning in higher education in Saudi Arabia: A study of Umm Al-Qura University. Unpublished doctoral dissertation, RMIT University, Melbourne, Victoria, Australia.

Almossa, S. Y. (2021). University students' perspectives toward learning and assessment during COVID-19. Education and Information Technologies. Published. https://doi.org/10.1007/s10639-021-10554-8

Alnahdi, A. (2019). Blended learning in Saudi Arabia-A review. Global Journal of Education and Training, 2(6), 1-7.

Alshehri, Y. A., Mordhah, N., Alsibiani, S., Alsobhi, S., \& Alnazzawi, N. (2020). How the regular teaching converted to fully online teaching in saudi arabia during the coronavirus covid-19. Creative Education, 11(7), 985-996.

Azizan, F. Z. (2010). Blended learning in higher education institution in Malaysia. In Proceedings of regional conference on knowledge integration in ICT (Vol. 10, pp. 454-466)

Bao, W. (2020). COVID-19 and online teaching in higher education: A case study of Peking University. Human Behavior and Emerging Technologies, 2(2), 113-115.

Bazelais, P., \& Doleck, T. (2018). Blended learning and traditional learning: A comparative study of college mechanics courses. Education and Information Technologies, 23(6), 2889-2900. https://doi.org/ 10.1007/s10639-018-9748-9

Bogle, L., Cook, V., Day, S., \& Swan, K. (2009). Blended program development: Applying the Quality Matters and Community of Inquiry Frameworks to ensure high quality design and implementation. Journal of the Research Center for Educational Technology, 5(2), 51-66.

Boyatzis, R. E. (1994). Stimulating self-directed learning through the managerial assessment and development course. Journal of Management Education, 18(3), 304-323.

Brackett, M. A., \& Rivers, S. E. (2014). Transforming students' lives with social and emotional learning. International handbook of emotions in education, 368.

De Ruyter, B., \& Aarts, E. (2004). Ambient intelligence: visualizing the future. In Proceedings of the working conference on Advanced visual interfaces (pp. 203-208).

Delmas, P., \& Moore, P. (2019). Student perceptions of video-based discussions in online and blended learning. In E-Learn: World Conference on E-Learning in Corporate, Government, Healthcare, and Higher Education (pp. 1280-1286). Association for the Advancement of Computing in Education (AACE).

Dickfos, J., Cameron, C., \& Hodgson, C. (2014) Blended learning: making an impact on assessment and self-reflection in accounting education. Education+ Training.

Fraenkel, J., Wallen, N., \& Hyun, H. (2018). How to Design and Evaluate Research in Education (10th ed.). McGraw-Hill Education.

Garrison, D. R. (2009). Communities of inquiry in online learning. In Encyclopedia of Distance Learning, Second Edition (pp. 352-355). IGI Global.

Garrison, D. R. (2015). Thinking collaboratively: Learning in a community of inquiry. Routledge.

Garrison, D. R., Anderson, T., \& Archer, W. (1999). Critical inquiry in a text-based environment: Computer conferencing in higher education. The Internet and Higher Education, 2(2-3), 87-105.

Garrison, D. R., Anderson, T., \& Archer, W. (2001). Critical thinking, cognitive presence, and computer conferencing in distance education. American Journal of Distance Education, 15(1), 7-23.

Garrison, D. R., \& Kanuka, H. (2004). Blended learning: Uncovering its transformative potential in higher education. The Internet and Higher Education, 7(2), 95-105.

Gopal, R., Singh, V., \& Aggarwal, A. (2021). Impact of online classes on the satisfaction and performance of students during the pandemic period of COVID 19. Education and Information Technologies. Published. https://doi.org/10.1007/s10639-021-10523-1

Heerink, M., Kröse, B., Evers, V., \& Wielinga, B. (2009). Influence of social presence on acceptance of an assistive social robot and screen agent by elderly users. Advanced Robotics, 23(14), 1909-1923.

Keskin, S. (2019). Factors affecting students' preferences for online and blended learning: Motivational vs. cognitive. European Journal of Open, Distance and E-Learning (EURODL), 22(2), 72-86. Fage. 
Khechine, H., Lakhal, S., Pascot, D., \& Bytha, A. (2014). UTAUT model for blended learning: The role of gender and age in the intention to use webinars. Interdisciplinary Journal of E-Learning and Learning Objects, 10(1), 33-52.

Kocaturk, T. (2017). A socio-cognitive approach to knowledge construction through blended learning. Journal of Problem Based Learning in Higher Education, 5(1)

Lam, J. Y. (2015). Autonomy presence in the extended community of inquiry. International Journal of Continuing Education and Lifelong Learning, 8(1), 39-61.

Law, K. M., Geng, S., \& Li, T. (2019). Student enrollment, motivation and learning performance in a blended learning environment: The mediating effects of social, teaching, and cognitive presence. Computers \& Education, 136, 1-12.

Leidner, D. E., \& Jarvenpaa, S. L. (1995). The use of information technology to enhance management school education: A theoretical view. MIS quarterly, 265-291

Mailizar, M., Burg, D., \& Maulina, S. (2021). Examining university students' behavioural intention to use e-learning during the COVID-19 pandemic: An extended TAM model. Education and Information Technologies. Published. https://doi.org/10.1007/s10639-021-10557-5

MOE. (2020). Retrieved from https://www.moh.gov.sa/Ministry/MediaCenter/News/Pages/News-2020-0328-001.aspx. Accessed 19 Jan 2021.

MOE 1. (2020). Retrieved from https://www.moe.gov.sa/ar/news/Pages/d-2020-763.aspx. Accessed 19 Jan 2021.

MOE 2. (2020). Retrieved from https://www.moe.gov.sa/ar/news/Pages/el-2020-u43.aspx. Accessed 19 Jan 2021.

Onah, D. F. O., Pang, E. L. L., \& Sinclair, J. E. (2020). Cognitive optimism of distinctive initiatives to foster self-directed and self-regulated learning skills: A comparative analysis of conventional and blendedlearning in undergraduate studies. Education and Information Technologies, 25(5), 4365-4380. https:// doi.org/10.1007/s10639-020-10172-w

Parkes, J., \& Harris, M. B. (2002). The purposes of a syllabus. College Teaching, 50(2), 55-61.

Patwardhan, V., Rao, S., \& Prabhu, N. (2020). Community of Inquiry (CoI) Framework and Course Design as Predictors of Satisfaction in Emergency Remote Teaching: Perspectives of Hospitality Management Students. Journal of E-Learning and Knowledge Society, 16(4), 94-103. ISSN 18266223.

Richardson, J., \& Swan, K. (2001). An examination of social presence in online learning: students' perceived learning and satisfaction. Paper presented at the American Educational Research Association, Seattle.

Saifuddin, S. R. (2019). An Investigation of Academics' and Administrators' Perceptions of Blended Pedagogies at Saudi Universities.

Saudi Vision (2030). Retrieved from https://vision2030.gov.sa/en. Accessed 19 Jan 2021.

Schmitt, N. (1996). Uses and abuses of coefficient alpha. Psychological Assessment, 8(4), 350.

SEU (n.d.). Retrieved from https://seu.edu.sa/en/blending-learn/. Accessed 19 Jan 2021.

Sharma, A., \& Alvi, I. (2021). Evaluating pre and post COVID 19 learning: An empirical study of learners' perception in higher education. Education and Information Technologies. Published. https://doi.org/10. 1007/s10639-021-10521-3

Shea, P., Li, C. S., Swan, K., \& Pickett, A. (2005). Developing learning community in online asynchronous college courses: The role of teaching presence. Journal of Asynchronous Learning Networks, 9(4), 59-82.

Siah, C., Lim, F., Lau, S., \& Tam, W. (2020). The use of the community of inquiry survey in blended learning pedagogy for a clinical skill-based module. Journal of Clinical Nursing, 30(3-4), 454-465. https:// doi.org/10.1111/jocn. 15556

Singh, H., \& Reed, C. (2001). A white paper: Achieving success with blended learning. Centra Software, 1, $1-11$.

Szeto, E. (2015). Community of Inquiry as an instructional approach: What effects of teaching, social and cognitive presences are there in blended synchronous learning and teaching? Computers \& Education, $81,191-201$.

Tanveer, M., Bhaumik, A., \& Hassan, S. (2020). Covid-19 pandemic, outbreak educational sector and students online learning in Saudi Arabia. Journal of Entrepreneurship Education, 23(3), 1-14.

Tulaboev, A. (2013). Blended learning approach with web 2.0 tools. In 2013 International Conference on Research and Innovation in Information Systems (ICRIIS) (pp. 118-122). IEEE.

Varela, O. E., Cater, J. J., \& Michel, N. (2012). Online learning in management education: An empirical study of the role of personality traits. Journal of Computing in Higher Education, 24(3), 209-225.

Venkatesh, V., Morris, M. G., Davis, G. B., \& Davis, F. D. (2003). User acceptance of information technology: Toward a unified view. MIS quarterly, 425-478. 
Wai, C. C., \& Seng, E. L. K. (2014). Exploring the effectiveness and efficiency of blended learning tools in a school of business. Procedia-Social and Behavioral Sciences, 123, 470-476.

Wilkinson, D., \& Birmingham, P. (2003). Using research instruments: A guide for researchers. Psychology Press.

Publisher's note Springer Nature remains neutral with regard to jurisdictional claims in published maps and institutional affiliations. 